\title{
Methods for Improved Flexural Mechanical Properties of 3D-Plotted PCL-Based Scaffolds for Heart Valve Tissue Engineering
}

\author{
Kim Ragaert 1,2,* - Filip De Somer ${ }^{3}$ - Stieven Van de Velde ${ }^{1}$ - Joris Degrieck ${ }^{2}$ - Ludwig Cardon ${ }^{1,2}$ \\ ${ }^{1}$ University College Ghent, Associated Faculty of Applied Engineering Sciences, Belgium \\ 2 Ghent University, Faculty of Engineering and Architecture, Belgium \\ 3 University Hospital Ghent, Heart Centre, Belgium
}

\begin{abstract}
While porous poly---caprolactone (PCL) scaffolds can be manufactured through 3D plotting with high regularity and reproducibility, it has been a challenge in previous research to mimic the highly flexible behaviour of the natural valve leaflets. In this study, an investigation is made of two separate approaches for the improved flexibility of 3D plotted PCL scaffolds for heart valve leaflets. Firstly, the scaffold geometry is radically altered towards a very open woven-like structure by adequately adapting the processing parameters during 3D plotting. Secondly, the base material itself is altered by blending a fraction of low-molecular weight poly-ethylene-oxide (PEO) into the PCL polymer. The scaffolds are $3 D$ plotted for both series and their flexibility is evaluated in a uni-axial indentation experiment. The results are compared to those of the natural valve tissue and it is found that both approaches result in the desired reduction of the stiffness of the scaffold.
\end{abstract}

Keywords: scaffolds, mechanical properties, flexure, heart valves, tissue engineering, 3D plotting

\section{INTRODUCTION}

A growing application of biodegradable polymers is the manufacture of scaffolds for tissue engineering, an advanced multidisciplinary research field meant to meet the growing demand for donor organs and tissues [1] to [3]. According to the tissue engineering principle, biodegradable scaffolds are used as support structures for the culture of the patient's harvested cells in an in vitro environment, so as to (re)create healthy tissues meant to replace diseased ones. While this neo-tissue grows, the scaffold slowly degrades into nontoxic components, eventually leaving only the new, functional and healthy tissue behind. This final construct can be implanted into the patient and will not solicit any rejection, because the cells used are the patient's own.

When looking to cardiovascular applications and more specifically to leaflets for heart valve replacement, the elastic-mechanical properties of the scaffold are just as important as the biodegradability and non-toxicity of the material. The leaflet must be strong enough to withstand the blood flow and at the same time be able to follow the elastic movement of a natural valve. In fact, when researching such valve scaffolds, we did not look for the strongest possible scaffold but for the highest possible compliance with the elastic-mechanical behaviour of natural tissue. Adherence to such compliant behaviour will provide the correct mechanical stimuli for the differentiation of the seeded cells.
Poly- $\varepsilon$-caprolactone (PCL) was selected as a base material for the scaffolds in this study because it is relatively flexible in comparison to other aliphatic polyesters and as such is considered more suitable for use with scaffolds for cardiovascular applications [4]. Moreover, it displays very good thermal stability, with a degradation temperature situated in the range of 280 to $330^{\circ} \mathrm{C}$ [5], which makes it very suitable for use with a melt processing technique like the micro-extrusion for 3D plotting proposed in this work. Finally, PCL is FDA-approved (by Food and Drug Administration); it is considered to be compatible with both hard and soft tissues [6] to [8] and will degrade slowly in the human body over a period of 24 to 36 months [9] to [11]. The main disadvantage of PCL is the strongly hydrophobic nature of its surface [12] to [14], which leads to nonspecific protein adsorption.

In previous research, different series of porous 4-layer PCL scaffolds were manufactured through 3D-plotting, with individual filament sizes from 127 to $410 \mu \mathrm{m}$ and spacing between filaments 1.8 times the filament size. It was found that while the scaffolds with the thinnest filaments best approximated the uniaxial mechanical properties of the natural valve cusp tissue, they generally remained too stiff to be viable as valve leaflet scaffolds [15] and [16]. Therefore, the focus of the current research is to further reduce the stiffness of the PCL scaffolds, by adapting either the scaffold geometry to a so-called woven-like structure or adapting the scaffold base material by blending PCL with low-molecular weight poly-ethylene-oxide 
(PEO), which is deemed an adequate choice for three reasons [17] to [19]:

i) The low molecular weight PEO fraction can reduce the mechanical properties of PCL, which will bring them closer to those of the natural valve cusp;

ii) $\mathrm{PEO}$ is hydrophilic in nature and can attenuate the hydrophobicity of PCL, a property which is known to be unbeneficial to the attachments of cells to the scaffolds due to non-specific protein absorption [20];

iii) PEO is biocompatible and water-soluble.

\section{MATERIALS AND METHODS}

\subsection{Materials}

For the scaffolds with woven-like geometry, PCL CAPA 6500 from Perstorp (UK) is used. The manufacturer reports a weight-averaged molecular weight of $84500 \mathrm{Da}$, a polydispersity of 1.78 and a maximum crystalline fraction of $56 \%$.

The PCL-PEO blends were developed by the Polymer Chemistry and Biomaterials (PBM) group at Ghent University: three solutions were prepared each with a different concentration of PEO: one, five and ten weight-percent (wt\%) PCL (Sigma AldrichBelgium, $\mathrm{Mn}=80000 \mathrm{Da}$ ) and PEO (Sigma AldrichBelgium, $\mathrm{Mn}=2000 \mathrm{Da}$ ) were first dissolved in chloroform, after which a precipitation reaction in cooled diethylether was performed. The different blends are hereafter referred to as PCL-PEO1, PCLPEO5 and PCL-PEO10, for their respective PEO contents. Characterisation of the composition of the synthesized PEO-PCL compounds was carried out using proton-nuclear magnetic resonance

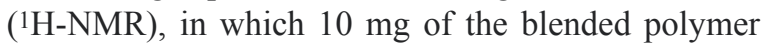
was dissolved in deuterated chloroform $\left(\mathrm{CDCl}_{3}\right)$ for the measurements. Tetramethylsilane (TMS) was used as an internal standard for calibrating the chemical shift. The experiments were performed on a WH 300 $\mathrm{MHz}{ }^{1} \mathrm{H}-\mathrm{NMR}$ apparatus (Bruker, Belgium) and were conducted in triplicate for each concentration type.

\subsection{D Plotting of Woven-Like Scaffolds}

Compared to the previous research, the porosity of the scaffolds is increased, the number of layers is reduced to three, and the plotting speed is adjusted so that the polymer filaments are placed similarly to those in a woven structure. These scaffolds are characterised by the term "woven-like geometry" for the purpose of this manuscript. They were manufactured using the BioScaffolder (SysEng, Germany), a 3D plotting device. The workings of this apparatus have been previously detailed [21]. In short, the machine melts the thermoplastic polymer in a mobile dispenser head and extrudes thin filaments that are deposited on a plotting table. The final product is built up layer-bylayer.

Concerning the porous geometry, the mounted extrusion needle had a diameter of $127 \mu \mathrm{m}$ and a strand distance (the centre-to-centre distance between two adjacent filaments) of $900 \mu \mathrm{m}$ was set. The most important processing parameters include a processing temperature of $125^{\circ} \mathrm{C}$, plotting speed of $85 \mathrm{~mm} / \mathrm{min}$, and an extrusion screw speed of $11 \mathrm{rpm}$.

From earlier research [22], it had become apparent that, as a rule-of-thumb, the strand distance should remain below twice the filament diameter for the different layers to provide sufficient support for the subsequent filaments to remain taut. By increasing the strand distance well above this practical limit, the filaments will sag into the underlying pores. Additionally, the plotting speed used is in fact too slow in comparison to the extrusion rate provided by the screw, allowing for sufficient material deposition to plot the sagging filaments without thinning or breaking. Together, these altered processing conditions create the woven-like structure of the scaffold, which is shown in Fig. 1.

The scaffolds were plotted to a square geometry of $15 \times 15 \mathrm{~mm}^{2}$, with three layers stacked according to a 0 to 90 pattern.

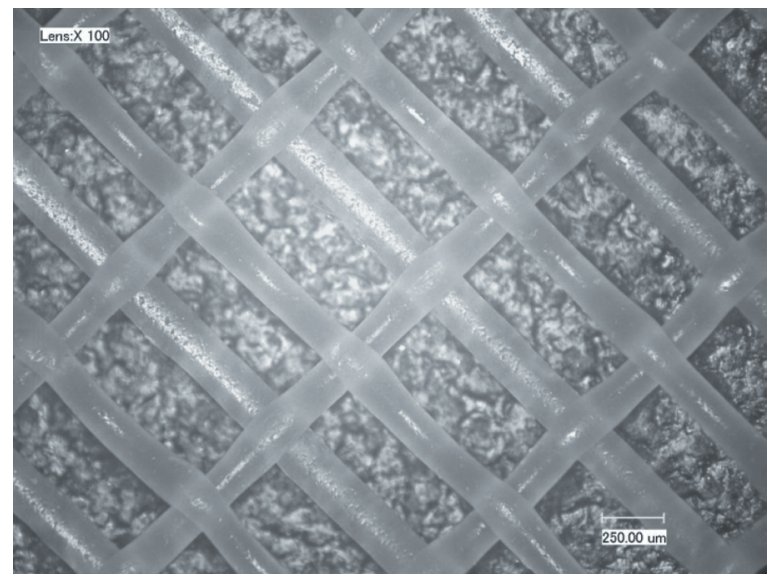

Fig. 1. The woven-like structure of the first series of modified PCL scaffolds

\subsection{D Plotting of PCL-PEO Scaffolds}

PCL-PEO scaffolds were produced on the same BioScaffolder apparatus. Only limited amounts of 
material were available, about four to five grams per blend type. As an optimization of the parameter set had to be done using up as little material as possible, the larger needle section of $200 \mu \mathrm{m}$ was chosen in order to avoid possible material flow problems. The strand distance was set at $360 \mu \mathrm{m}$ and the extrusion temperature at $115{ }^{\circ} \mathrm{C}$. Processing parameters were further fine-tuned for each blend. In general, the plotting speed and extruder screw ratio were reduced for higher PEO contents, which displayed a more viscous behaviour. The dispenser head was disassembled and cleaned for every material changeover.

Scaffolds were plotted to a square geometry of $15 \times 15 \mathrm{~mm}^{2}$, with four layers stacked according to a 0 to 90 pattern. Some scaffolds were also manufactured using pure PCL to obtain a reference value for the mechanical properties of the unblended PCL.

\subsection{Mechanical Properties}

The experimental setup and the principle of the flexural indentation test are shown in Fig. 2. The tissue is placed over a round hole, where it is held in place by a half-sunk rubber ring and fixed in place by a clamping plate. The tissue is then indented by a descending ball probe, to which the central hole has been aligned. Three tissue properties are derived from the test:

i) Extension at break $[\mathrm{mm}](E X T)$ : the depth of indentation by the probe at the moment of rupture (defined as a sudden decrease in load by $50 \%$ );

ii) Maximum load $[\mathrm{N}](M L)$ : the maximum load which can be applied to the cusp prior to rupture;

iii) Stiffness parameter $[\mathrm{N} / \mathrm{mm}](S T)$ : the slope of the linear section of the indentation-load curve. This is a measure for the stiffness of the tissue.

$M L$ and EXT describe the ultimate properties of the cusps. $S T$ on the other hand describes the flexural response of the leaflet under an applied load and provides the most valuable information when considering the physiological functionality of the tissue.

All tests were performed on an LF Plus Universal material tester (Lloyd Instruments, UK), with a load cell of $1 \mathrm{kN}$, a ball probe of $4.45 \mathrm{~mm}$ in diameter and an indentation speed of $25 \mathrm{~mm} / \mathrm{min}$. The ball probe was lowered onto the centre of the hole until perforation, which was defined as a sudden decrease in load by $50 \%$. A lower force limit of $0.1 \mathrm{~N}$ was set as the zero-indentation point for the scaffold. Force and displacement of the ball probe were recorded and used for the calculation of $M L, E X T$ and $S T$. Per series, three scaffolds were tested and their results averaged. All results are represented as the mean \pm the standard deviation.

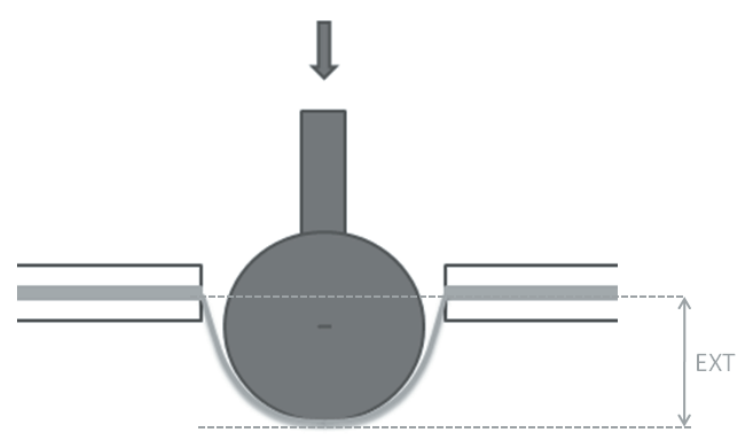

Fig. 2. Principles of the uni-axial indentation test. Reprinted from [23] with permission (Elsevier)

The results are compared to the respective values for the natural valve cusp tissue [23], which can be found in Table 1.

Table 1. Mechanical properties for the PCL-PEO scaffolds, compared to those of the natural cusp

\begin{tabular}{cccc}
\hline$\%$ PE0 & EXT $[\mathrm{mm}]$ & $M L[\mathrm{~N}]$ & $S T[\mathrm{~N} / \mathrm{mm}]$ \\
\hline 1 & $2.72 \pm 0.10$ & $28.26 \pm 0.50$ & $11.65 \pm 0.20$ \\
\hline 5 & $2.60 \pm 0.08$ & $24.88 \pm 1.32$ & $11.12 \pm 0.02$ \\
\hline 10 & $2.57 \pm 0.12$ & $24.34 \pm 1.58$ & $10.42 \pm 0.49$ \\
\hline natural cusp & $3.26 \pm 0.64$ & $13.05 \pm 4.48$ & $5.97 \pm 1.69$ \\
\hline
\end{tabular}

\subsection{Characterization of PCL-PEO Scaffolds}

Characterization experiments on the PCL-PEO scaffolds were carried out by the PBM group. A visualization of the scaffold surfaces was carried out using a scanning electron microscope (SEM, JEOL JSM-5600 microscope) with the apparatus in secondary electron mode (SEI). Prior to analysis all samples were coated with a gold layer of approximately $20 \mathrm{~nm}$.

$\mathrm{X}$-ray photon spectroscopy (XPS) is a technique that allows the determination of the elemental composition of the outermost 10 to $15 \mathrm{~nm}$ of a surface. XPS measurements were performed with an ESCA S-probe VG monochromatised spectrometer (with an $\mathrm{Al} \mathrm{K \alpha}$ source X-ray source of $1486 \mathrm{eV}$ ) on the scaffolds of all three blend-types. A survey scan spectrum was collected and from the peak-area ratios, the relative elemental composition of the material's top layer was determined. 


\section{RESULTS AND DISCUSSION}

\subsection{Properties of the woven-like scaffolds}

The results for the woven-like scaffolds are shown in Fig. 3, in which slanted S-shaped curves may be discerned for all scaffolds. After an initial low-force response, the scaffolds stiffen into a linear flexural behaviour, which is topped off by the final plateau, representative of the rupture of the scaffold by the ball probe. The deduced mechanical properties for the woven-like scaffolds are: $E X T=2.23 \pm 0.10 \mathrm{~mm}, M L$ $=5.51 \pm 0.07 \mathrm{~N}$ and $S T=3.79 \pm 0.17 \mathrm{~N} / \mathrm{mm}$.

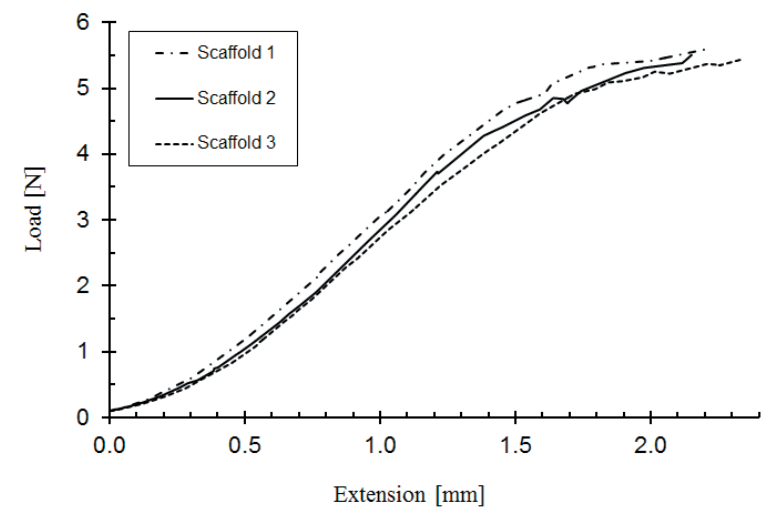

Fig. 3. Results for the woven-like scaffolds

As described earlier, the stiffness parameter $S T$ is considered to best reflect the flexural behaviour of the leaflet. The $S T$ value is significantly lower than that of the natural cusp tissue. This is, however, considered a positive evolution and an important one at that. In previous research [15], the lowest value achieved (4-layered PCL scaffolds with the same filament size) was $11 \mathrm{~N} / \mathrm{mm}$, well above the range of the natural tissue. It was also found that, with the 3D plotted scaffolds, the stiffness of the construct is easily increased by lowering the strand distance or by using thicker individual filaments. The limitation has always been that the stiffness could not be sufficiently reduced. By creating an open woven-like structure, a lower ST value has been realised for the first time. It is expected that this value can easily be raised again by modifying the geometry towards a more dense structure.

\subsection{Composition of the PCL-PEO Blends}

Examples of the ${ }^{1} \mathrm{H}-\mathrm{NMR}$ spectra of the three blends are shown in Fig. 4. The peak at a chemical shift of around $3.6 \mathrm{ppm}$, which can be seen to increase with rising amounts of $\mathrm{PEO}$, is attributed to the methylene protons of the $-\mathrm{CH}_{2}-\mathrm{CH}_{2} \mathrm{O}$ - in the $\mathrm{PEO}$ chain structure [24].
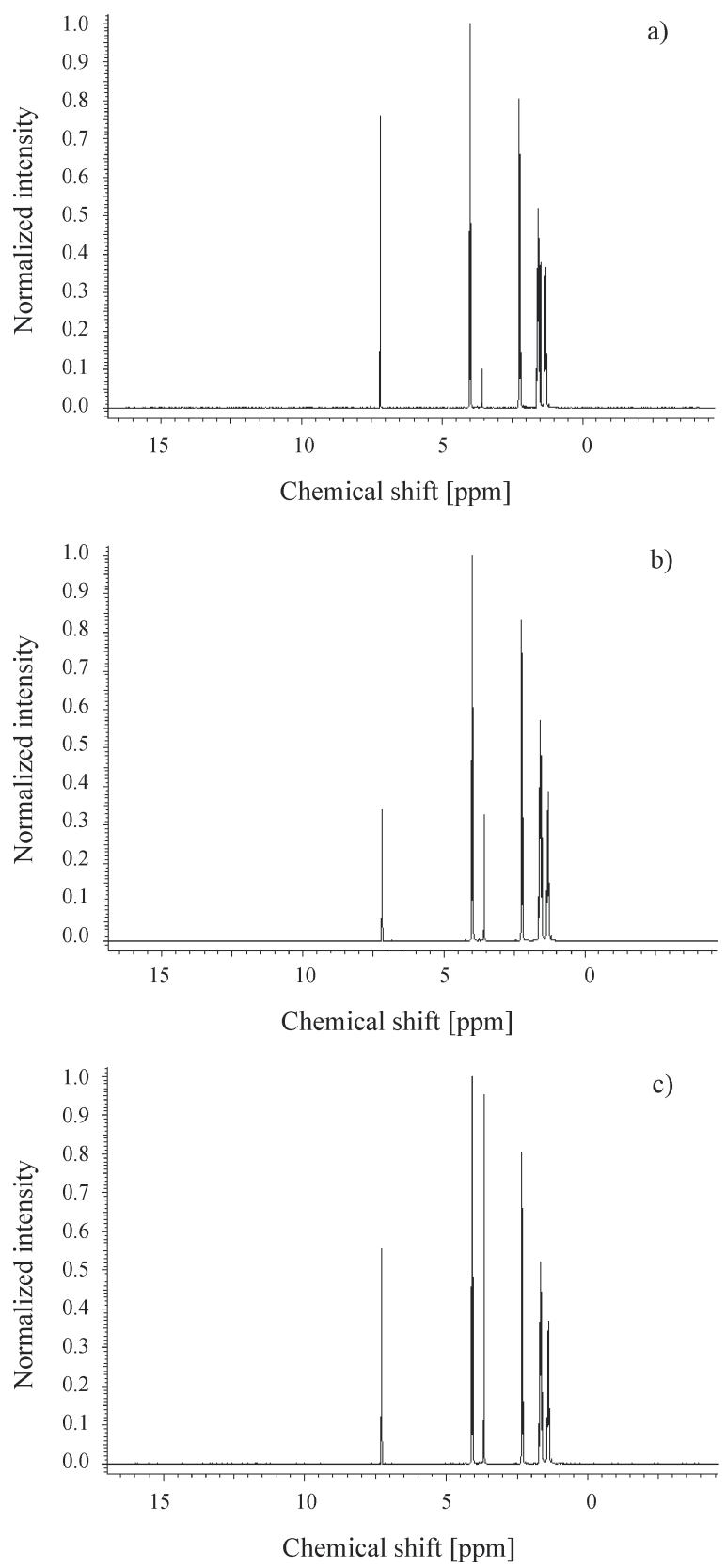

Fig. 4. Sample 1 H-NMR spectra; a) PCL-PE01, b) PCL-PE05, c) PCL-PE010

The resulting calculations of the weight percentage of $\mathrm{PEO}$ in the different blends from the ${ }^{1} \mathrm{H}-\mathrm{NMR}$ spectra yield the following results: $0.90 \pm 0.05 \%$ for PCL-PEO1, $4.53 \pm 0.42 \%$ for 
PCL-PEO5 and $9.21 \pm 0.45 \%$ for PCL-PEO10. The preparation of the PEO-PCL blends can therefore be considered successful, with the resulting PEO concentrations within $10 \%$ of their set value.

\subsection{Properties of the PCL-PEO Blended Scaffolds}

The PCL-PEO scaffolds display a similar type of flexural behaviour, but are clearly more resilient to higher levels of load. The load-displacement curves of PCL-PEO10 are shown in Fig. 5 as an example.

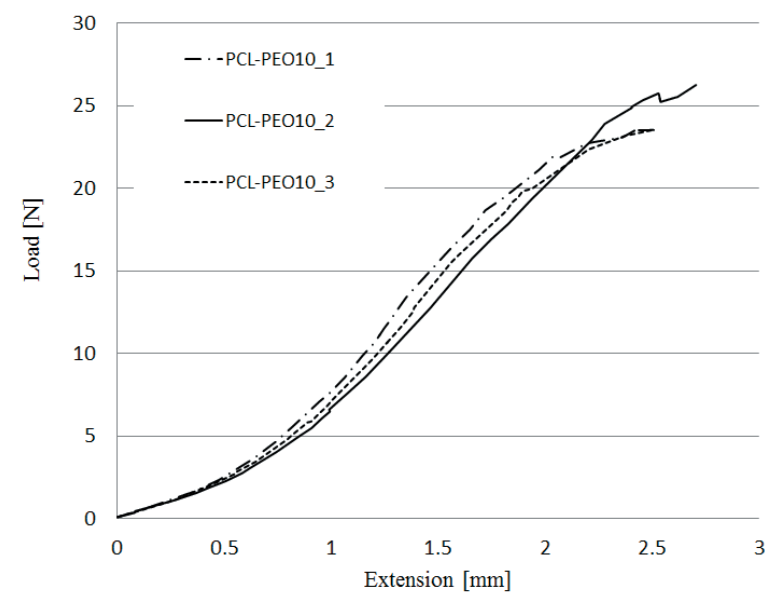

Fig. 5. Results for the load-displacement for PCL-PEO10 scaffolds

The calculated values of EXT, ML and $S T$ are listed in Table 1 per blend type. All three properties can be seen to decrease with an increasing percentage of PEO mixed into the blend.

The decrease in ST, the parameter that is most relevant for the flexural behaviour under operating conditions, appears to be directly related to the amount of PEO in the blend. This is illustrated in Fig. 6, where the equation of the linear fit to the curve is also displayed. It implies that for the unblended PCL, the ST value would be $11.79 \mathrm{~N} / \mathrm{mm}$. This value matches the ST value found for the unblended PCL scaffolds, which was $11.64 \pm 0.20 \mathrm{~N} / \mathrm{mm}$.

From these results, it is apparent that the addition of a low-molecular weight PEO fraction leads to a proportional reduction in the compound's - and therefore the scaffold's - stiffness. It may be possible to use this plasticizing effect of PEO in order to obtain mechanical properties more like those of the natural tissue. It must be remarked that PEO is soluble in water and will dissolve within 24 hours if submerged [17]. This means that the PEO component should not be counted upon for structural integrity once the scaffold had been placed within a medium for cell culturing. Disintegration of the PEO fraction will result in a porous PCL scaffold that must also remain structurally intact and fully functional. As such, PEO concentrations can never be too high within the blend. It would be advisable for further research to include a study of the effect of PEO removal from the scaffold on the structure and the mechanical properties.

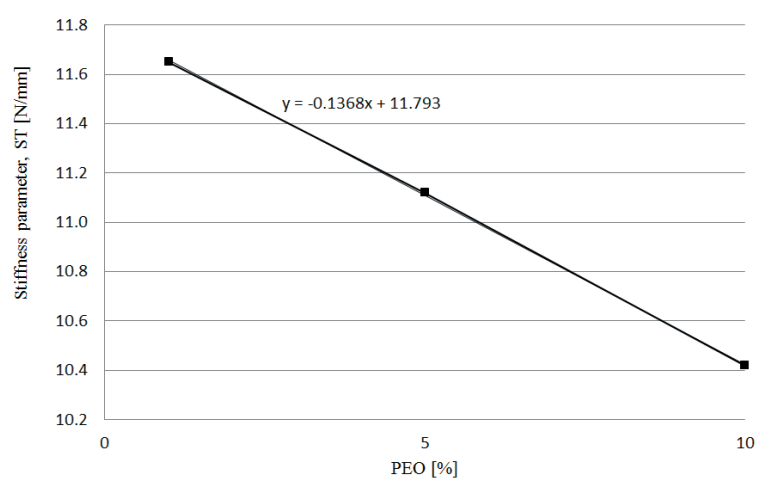

Fig. 6. Relation between ST and wt\% PEO

\subsection{Characterization of the PCL-PEO Scaffolds}

SEM-images of the PCL-PEO struts are shown in Fig. 7 to 9 for 1,5 and $10 \mathrm{wt} \%$ of PEO respectively. For the PCL_PEO1 scaffold, a more or less smooth surface is seen, with some protruding material regions in the middle left of the image. This local surface roughness is caused by precipitates of PEO, the amount of which can be observed to increase sharply as the PEO concentration rises; the surface of the PCL_PEO10 scaffolds is covered almost entirely by these precipitates.

Because of the roughness the precipitates induce on the surface, a higher signal in the SEM-image is obtained, which results in white pigments on the struts in the images with magnification $\times 75$.

This relatively large impact of the PEO fraction on the surface condition of the filaments would suggest that the PEO is mostly located at the surface of the extruded strut and no longer homogenously distributed throughout it.

This assumption is confirmed by the XPS results. The different high-resolution carbon XPS spectra of PCL-PEO1, PCL-PEO5 and PCL-PEO10 are shown in Fig. 10 . The spectra of these blends are compared to those of pure PCL and PEO, which have been reported by Manso et al. [25]. 


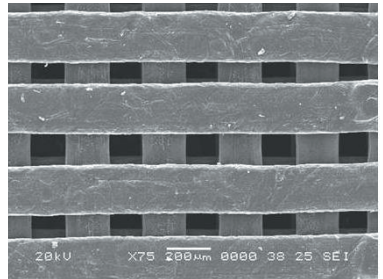

(a)

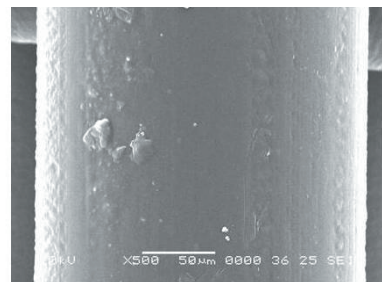

(b)
Fig. 7. SEM-images of the PCL-PEO1 scaffolds; a) top view ( $\times 75)$, b) view of a strut $(\times 500)$

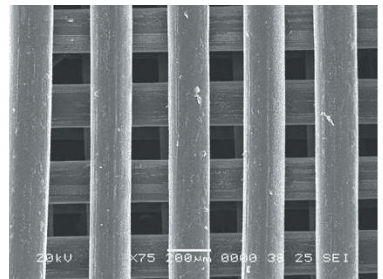

(a)

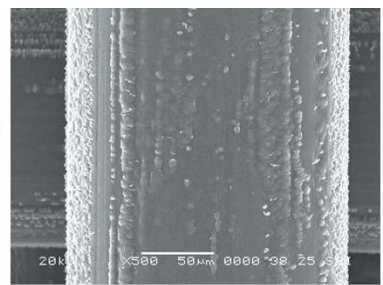

(b)
Fig. 8. SEM-images of the PCL-PEO5 scaffolds; a) top view ( $\times 75)$, b) view of a strut $(\times 500)$

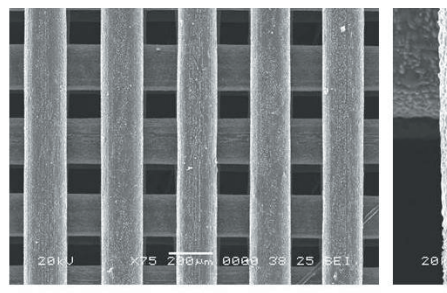

(a)

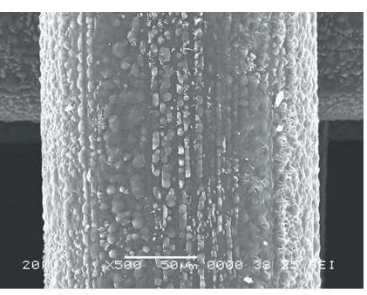

(b)
Fig. 9. SEM-images of the PCL-PE010; (a) top view ( $\times 75)$, (b) view of a strut $(\times 500)$

The peak at $289.1 \mathrm{eV}$, which can be attributed to carboxylic functional groups $(\mathrm{O}-\mathrm{C}=\mathrm{O})$, is considered indicative of PCL; it is strongly pronounced in the spectrum of pure PCL [26]. The peak at $286.5 \mathrm{eV}$ is very dominant for the spectrum of pure PEO and is considered to be representative of the presence of $\mathrm{PEO}$, as it dominates the $\mathrm{C}-\mathrm{O}$ bond [26]. Finally, the peak at $284.8 \mathrm{eV}$ is found in the spectrum of both pure materials, as it indicates bonds which both polymers have in their structure (mainly C-H) [26]. With rising amounts of PEO added to the blend, the relative peak area representing PEO can be seen to increase at the cost of the peak indicating the presence of PCL. Table 2 shows the assignments for the quantitative deconvolution of the carbon spectra of the PCLPEO10.

The peak at $286.5 \mathrm{eV}$, which indicates the presence of PEO, corresponds to over $60 \%$ of the material surface. This is disproportionately high with regard to the amount of the blended polymer $(10 \%)$.
It was therefore concluded that the PEO fraction must have segregated within the blend and moved towards the surface, a phenomenon which is known as viscous encapsulation (phase separation) [27] and has been previously noted in the literature on PCL-PEO polymers [28].
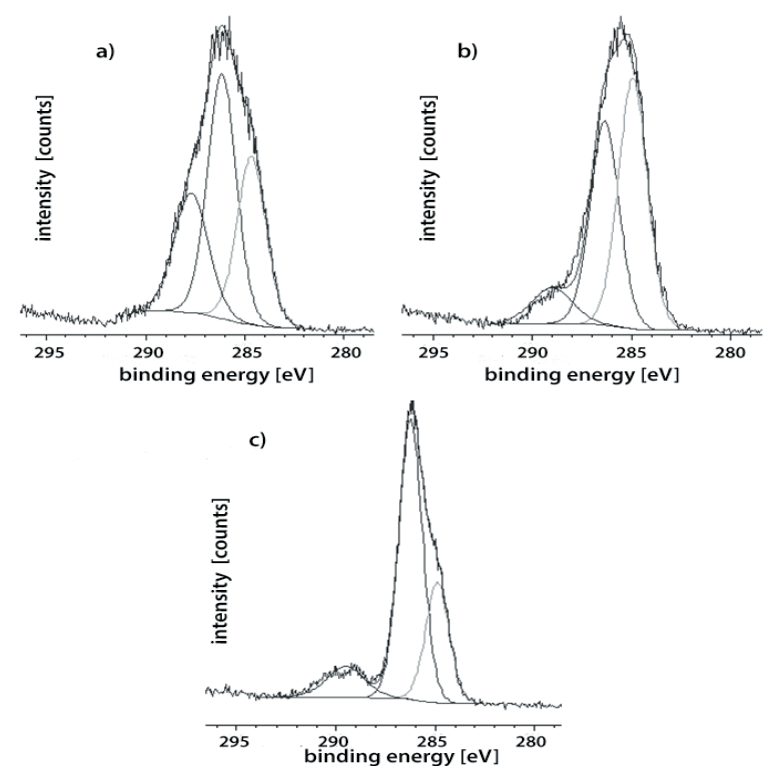

Fig. 10. XPS-spectra of; a) PCL-PE01, b)PCL-PE05, and c) PCLPE010

Table 2. The position and representative atom concentration of the peaks of the XPS-spectrum of PCL-PE010 (Fig. 10c)

\begin{tabular}{cccc}
\hline Position $(\mathrm{eV})$ & \% at conc. & Bond & Presence of \\
\hline 284.8 & 26.74 & $\mathrm{C}-\mathrm{O}, \mathrm{C}-\mathrm{C} / \mathrm{C}-\mathrm{H}$ & $\mathrm{PEO}, \mathrm{PCL}$ \\
\hline 286.5 & 62.43 & $\mathrm{C}-\mathrm{C} / \mathrm{C}-\mathrm{H}, \mathrm{C}-0$ & $\mathrm{PEO}$ \\
\hline 289.1 & 10.82 & $\mathrm{O}-\mathrm{C}=0$ & $\mathrm{PCL}$ \\
\hline
\end{tabular}

\subsection{Prospects}

The two approaches of adapting the geometry and the base material have been successful in improving the flexibility of the PCL-based leaflet scaffolds. By creating an extremely open woven-like structure it was even possible to create mechanical properties lower than those of the natural tissue, a feat that had not been accomplished for 3D-plotted PCL-based scaffolds prior to this research.

Tried separately, it was evident that addition of a low-molecular weight PEO fraction into the polymer blend also resulted in a reduction of the high $S T$ value of the scaffolds of more conventional and coarser geometries.

As such, both approaches have been shown valid for further investigation and the combination of the 
two approaches should allow for a broad range of flexible-mechanical properties to be realized.

However, some relevant expected effects of the PEO blending have not been investigated, such as the leaching out of the PEO fraction in a physiological environment. This would result in an additional in vitro/in vivo weakening of the construct and a more micro-porous scaffold surface, the latter of which may actually be beneficial to cell attachment.

Furthermore, these experiments have shown that even though blends of PCL-PEO are manufactured as a homogenous mix, processing them into filaments for 3D plotting by micro-extrusion will cause the PEO fraction to segregate out onto the surface of the struts. As hydrophilicity and surface roughness are observed to increase with the inclusion of more PEO, this encapsulation effect may be beneficial to the cellattractiveness of plotted PCL-based scaffolds.

\section{CONCLUSIONS}

In this exploratory study it has been found that the stiffness of PCL-based scaffolds can be reduced by (i) adapting the scaffold geometry to an open woven-like structure, as well as by (ii) altering the base material by blending in lower-strength polymer fractions.

By creating a more open structure and allowing the individual filaments to sag into the underlying pores it has - for the first time within the scope of this research - been possible to manufacture PCL scaffolds with flexural stiffness values that are lower than those of the natural tissue, thus overcoming the ongoing problem of PCL's higher stiffness than the natural cusp.

Additionally, the blending of PEO into PCL has been found to further increase the flexibility of the base material at a rate which is proportional to the amount of PEO added. Moreover, the shorter PEO chains have been found to migrate towards the surface of the extruded filaments, where they can contribute to the hydrophilicity of the scaffold surface.

In future, combining these aspects of geometry and material will allow for a more exact mimicking of the natural tissue's flexible behaviour by leaflet scaffolds.

\section{ACKNOWLEDGEMENTS}

The authors wish to acknowledge Professor Peter Dubruel and his research team of the PBM lab at Ghent University for supplying and characterizing the PCL-PEO blends. This research was funded by University College Ghent.

\section{REFERENCES}

[1] Langer, R., Vacanti, J.P. (1993). Tissue Engineering. Science, vol. 260, no. 5110, p. 920-926.

[2] Mikos, A.G., Temenoff, J.S. (2000). Formation of highly porous biodegrdable scaffolds for tissue engineering. Electronic Journal of Biotechnology, vol. 3, no. 2, p. 1-6, DOI:10.2225/vol3-issue2-fulltext-5.

[3] Isenberg, B.C., Wong, J.Y. (2006). Building structure into engineered tissues. Materials Today, vol. 9, no. 12, p. 54-60, DOI:10.1016/S1369-7021(06)71743-6.

[4] Brody, S., Pandit, A. (2007). Approaches to heart valve tissue engineering scaffold design. Journal of Biomedical Materials Research Part B-Applied Biomaterials, vol. 83B, no. 1, p. 16-43, DOI:10.1002/ jbm.b.30763.

[5] Sivalingam, G., Madras, G. (2003). Thermal degradation of poly (epsilon-caprolactone). Polymer Degradation and Stability, vol. 80, no. 1, p. 11-16, DOI:10.1016/S0141-3910(02)00376-2.

[6] Eshraghi, S., Das, S. (2010). Mechanical and microstructural properties of polycaprolactone scaffolds with one-dimensional, two-dimensional, and three-dimensional orthogonally oriented porous architectures produced by selective laser sintering. Acta Biomaterialia, vol. 6, no. 7, p. 2467-2476. DOI:10.1016/j.actbio.2010.02.002.

[7] Guarino, V., Causa, F., Taddei, P., di Foggia, M., Ciapetti, G., Martini, D., Fagnano, C., Baldini, N., Ambrosio, L. (2008). Polylactic acid fibre-reinforced polycaprolactone scaffolds for bone tissue engineering. Biomaterials, vol. 29, no. 27, p. 3662-3670. DOI:10.1016/j.biomaterials.2008.05.024.

[8] Wang, Z.W., Su, J.C., Ma, Y.H., Zhang, X., Cao, L.H., Li, M. (2010). Preparation and Properties of Nano Calcium Deficient Apatite/Poly (epsilon-caprolactone) Composite Scaffold. Journal of Inorganic Materials, vol. 25, no. 5, p. 500-506, DOI:10.3724/ sp.j.1077.2010.00500.

[9] Stankus, J., Guan, J., Wagner, W. (2004). Biodegradable Elastomers. Wnek, G., Bowlin, G. (eds.), Encyclopedia of Biomaterials and Biomedical Engineering, Marcel Dekker: Richmond. p. 484-494.

[10] Lam, C.X.F., Hutmacher, D.W., Schantz, J.T., Woodruff, M.A., Teoh, S.H. (2009). Evaluation of polycaprolactone scaffold degradation for 6 months in vitro and in vivo. Journal of Biomedical Materials Research Part A, vol. 90A, no. 3, p. 906-919, DOI:10.1002/jbm.a.32052.

[11] Nair, L.S., Laurencin, C.T. (2007). Biodegradable polymers as biomaterials. Progress in Polymer Science, vol. 32, no. 8-9, p. 762-798.

[12] Lee, H., Kim, G. (2010). Biocomposites Electrospun with Poly(epsilon-caprolactone) and Silk Fibroin Powder for Biomedical Applications. Journal of Biomaterials Science-Polymer Edition, vol. 21, no. 13 , p. 1687-1699, DOI:10.1163/09205060 9x12548956645680. 
[13] Shan, X.Q., Yuan, Y., Liu, C.S., Tao, X.Y., Sheng, Y., Xu, F. (2009). Influence of PEG chain on the complement activation suppression and longevity in vivo prolongation of the PCL biomedical nanoparticles. Biomedical Microdevices, vol. 11, no. 6, p. 1187-1194, DOI:10.1007/s10544-009-9336-2.

[14] Yao, K.J., Wang, J.F., Zhang, W.J., Lee, J.S., Wang, C.P., Chu, F.X., He, X.M., Tang, C.B. (2011). Degradable Rosin-Ester-Caprolactone Graft Copolymers. Biomacromolecules, vol. 12, no. 6, p. 2171-2177, DOI:10.1021/bm200460u.

[15] Ragaert, K., De Somer, F., De Baere, I., Cardon, L., Degrieck, J. (2011). Production \& Evaluation of PCL Scaffolds for Tissue Engineered Heart Valves. APEM, vol. 6 , no. 3 , p. 163-172.

[16] Ragaert, K., Cardon, L., De Somer, F., Degrieck, J. (2010). PCL leaflets for tissue engineered heart valves: $3 \mathrm{D}$ plotting and mechanical properties. PMI, p. 308312.

[17] Kim, G., Park, J.H., Park, S. (2007). Surface-treated and multilayered poly(epsilon-caprolactone) nanofiber webs exhibiting enhanced hydrophilicity. Journal of Polymer Science Part B-Polymer Physics, vol, 45, no. 15, p. 2038-2045, DOI:10.1002/polb.21211.

[18] Guarino, V., Netti, P.A., Ambrosio, L. (2008). Development of highly oriented porous structures by PCL/PEO co-continuous blends. Acierno, D., Damore, A., Grassia, L. (eds), IVth International Conference on Times of Polymers. p. 201-203.

[19] Reignier, J., Huneault, M.A. (2006). Preparation of interconnected poly(epsilon-caprolactone) porous scaffolds by a combination of polymer and salt particulate leaching. Polymer, vol. 47, no. 13, p. 47034717, DOI:10.1016/j.polymer.2006.04.029.

[20] Desmet, T., Billiet, T., Berneel, E., Cornelissen, R., Schaubroeck, D., Schacht, E., Dubruel, P. (2010). Post-Plasma Grafting of AEMA as a Versatile Tool to Biofunctionalise Polyesters for Tissue Engineering. Macromolecular Bioscience, vol. 10, no. 12, p. 14841494, DOI:10.1002/mabi.201000147.
[21] Ragaert, K., Cardon, L., Dekeyser, A., Degrieck, J. (2010). Machine design \& processing considerations for the 3D plotting of thermoplastic scaffolds. Biofabrication, vol. 2, no. 1, DOI:10.1088/17585082/2/1/014107.

[22] Ragaert, K. (2011). Micro-Extrusion of Thermoplastics for 3D Plotting of Scaffolds for Tissue Engineering. Ghent University, Department of Materials Science and Engineering, Ghent.

[23] Ragaert, K., De Somer, F., Somers, P., De Baere, I., Cardon, L., Degrieck, J. (2012). Flexural mechanical properties of porcine aortic heart valve leaflets. Journal of the Mechanical Behavior of Biomedical Materials, vol. 13, no. 0, p. 78-84, DOI:10.1016/j. jmbbm.2012.04.009.

[24] Ma, G., Miao, B., Song, C. (2010). Thermosensitive PCL-PEG-PCL hydrogels: Synthesis, characterization, and delivery of proteins. Journal of Applied Polymer Science, vol. 116, no. 4, p. 1985-1993, DOI:10.1002/ app. 31654 .

[25] Manso, M., Valsesia, A., Lejeune, M., Gilliland, D., Ceccone, G., Rossi, F. (2005). Tailoring surface properties of biomedical polymers by implantation of $\mathrm{Ar}$ and He ions. Acta Biomaterialia, vol. 1, no. 4, p. 431-440, DOI:10.1016/j.actbio.2005.03.003.

[26] Cheng, Z., Teoh, S.-H. (2004). Surface modification of ultra thin poly ([var epsilon]-caprolactone) films using acrylic acid and collagen. Biomaterials, vol. 25, no. 11, p. 1991-2001, DOI:10.1016/j. biomaterials.2003.08.038.

[27] Moroni, L. (2006). A Mechanistic Approach to Design Smart Scaffolds for Tissue Engineering. University of Twente: Enschede.

[28] Li, G.M., Cai, Q., Bei, J.Z., Wang, S.G. (2002). Relationship between morphology structure and composition of polycaprolactone/poly (ethylene oxide)/ polylactide copolymeric microspheres. Polymers for Advanced Technologies, vol. 13, no. 9, p. 636-643, DOI:10.1002/pat.287. 